\title{
Hydraulic conductivity and contribution of aquaporins to water uptake in roots of four sunflower genotypes
}

\author{
Afifuddin Latif Adiredjo ${ }^{1,2}$, Olivier Navaud ${ }^{3}$, Philippe Grieu ${ }^{1}$ and Thierry Lamaze ${ }^{3 *}$
}

\begin{abstract}
Background: This article evaluates the potential of intraspecific variation for whole-root hydraulic properties in sunflower. We investigated genotypic differences related to root water transport in four genotypes selected because of their differing water use efficiency (JAC doi: 10.1111/jac.12079. 2014). We used a pressure-flux approach to characterize hydraulic conductance $\left(L_{0}\right)$ which reflects the overall water uptake capacity of the roots and hydraulic conductivity $\left(L p_{r}\right)$ which represents the root intrinsic water permeability on an area basis. The contribution of aquaporins (AQPs) to water uptake was explored using mercuric chloride $\left(\mathrm{HgCl}_{2}\right)$, a general AQP blocker.

Results: There were considerable variations in root morphology between genotypes. Mean values of $L_{0}$ and $L p_{r}$ showed significant variation (above $60 \%$ in both cases) between recombinant inbred lines in control plants. Pressure-induced sap flow was strongly inhibited by $\mathrm{HgCl}_{2}$ treatment in all genotypes (more than 50\%) and contribution of AQPs to hydraulic conductivity varied between genotypes. Treated root systems displayed markedly different $L_{0}$ values between genotypes whereas $L p_{r}$ values were similar.

Conclusions: Our analysis points to marked differences between genotypes in the intrinsic aquaporin-dependent path ( $L p_{r}$ in control plants) but not in the intrinsic AQP-independent paths $\left(L p_{r}\right.$ in $\mathrm{HgCl}_{2}$ treated plants). Overall, root anatomy was a major determinant of water transport properties of the whole organ and can compensate for a low AQP contribution. Hydraulic properties of root tissues and organs might have to be taken into account for plant breeding since they appear to play a key role in sunflower water balance and water use efficiency.
\end{abstract}

Keywords: Sunflower; Aquaporins; Root; Hydraulic conductivity

\section{Background}

Terrestrial plants are dependent on essential leaf physiological processes such as a continuous supply with water since photosynthesis cannot be dissociated from transpiration. Water balance at the whole plant level should be regulated by coupled responses between the aboveground and below-ground parts (Shimizu et al. 2005). In the soil-plant-atmosphere continuum, the root offers the second largest resistance to water transport after the stomata (Steudle et al. 1987). Thus, gaining information on the hydraulic properties of roots might be a key step for understanding whole-plant water relations and selection

\footnotetext{
* Correspondence: thierry.lamaze@cesbio.cnes.fr

${ }^{3}$ Université de Toulouse, UPS - Toulouse III, UMR 5126 CESBIO, 18 avenue

Edouard Belin, Toulouse, Cedex 9 31401, France

Full list of author information is available at the end of the article
}

of water stress-resistant species or genotypes and therefore plant breeding (Sutka et al. 2011).

In roots in which the xylem vessels are fully developed, the resistance to water transport occurs radially (Steudle and Peterson 1998; Ruggiero et al. 2003). Radial transport in roots crosses both the cell-to-cell pathway and the apoplastic pathway. The cell-to-cell route is composed of the symplastic (through the plasmodesmata) and the transcellular (involving crossing of membranes) paths. The apoplastic pathway is usually considered to have the least hydraulic resistance and is often considered to be the main route (Heinen et al. 2009). However, the presence of lignified or suberized cell walls (casparian strips in root endodermis) which constitute apoplastic barriers forces water to cross cell membranes (Shimizu et al. 2005). Several studies have attributed an important role to the cell-tocell path. Water movement through cell membranes is 
facilitated by water channels, called "aquaporins" (AQPs) (Maurel 2007). AQPs are integral membrane proteins that increase the permeability of membranes to water as well as other small molecules such as $\mathrm{CO}_{2}$, glycerol and boron (Shimizu et al. 2005; Chaumont et al. 2005). AQP proteins contain thiol groups that are sensitive to $\mathrm{HgCl}_{2}$ (Savage and Stroud 2007). Assuming that mercurial inhibition of water transport occurs via the inhibition of AQPs, the strength of inhibition may indicate the extent to which the cell-to-cell (transcellular) water movement (involving water passing through membranes) is involved in the radial transport of water across the root. Therefore, to divide radial water transport in roots into cell-to-cell and apoplastic pathways, $\mathrm{HgCl}_{2}$ has often been used as a specific AQP inhibitor in crops, herbs and trees (Maggio and Joly 1995; Carvajal et al. 1996; Tazawa et al. 1997; Zhang and Tyerman 1999; Wan and Zwiazek 1999; North et al. 2004; Kamaluddin and Zwiazek 2001; Shimizu et al. 2005; Sutka et al. 2011).

Intraspecific root water transport has so far been compared in only a small number of species: rice, maize, grapevine and Arabidopsis (Sutka et al. 2011). Sunflower is an economically important crop consumed worldwide. Although it is considered to be relatively tolerant to water stress, sunflower production can be greatly affected by drought (Pasda and Diepenbrock 1990; Grieu et al. 2008). Indeed, although sunflower extracts water efficiently and then conducts it within the plant, rates of leaf transpiration can reach very high values: up to $22 \mathrm{mmol} \mathrm{H}_{2} \mathrm{O} \mathrm{m}^{-2} \mathrm{~s}^{-1}$ (Rawson et al. 1980). It has been shown that AQPs play a role in the sunflower response to drought in both the leaf and the root (Ouvrard et al. 1996; Sarda et al. 1997, 1999). Information on the hydraulic properties of roots might be important for plant breeding. Thus, the aim of the present work was to evaluate the variations in the root hydraulic properties of four sunflower genotypes selected because of their differing whole-plant water relations under well-watered conditions (Adiredjo et al. 2014). We used pressureinduced flow through root systems since the method has been widely employed to measure the hydraulic properties of roots in various plant species. The contribution of the AQP-dependent pathway (cell-to-cell route) to water transport was characterized using mercuric chloride (mercury) as an inhibitor.

\section{Methods}

\section{Plant source}

Four recombinant inbred lines (RILs) of sunflower (Helianthus annuus L.) from the collection of the Laboratory of Plant-Microbe Interactions (LIPM), INRA of Toulouse, France, were used in the experiments, namely: RIL 043, RIL 127, RIL 149 and RIL 200. The four RILs are lines from the INEDI RIL population. This population was obtained by self pollination to at least F8 from a cross between XRQ and PSC8 (Vincourt et al. 2012). These parental lines have different drought tolerance behavior (Rengel et al. 2012). The four RILs were chosen on the basis of their differing water use efficiency (WUE) response under well-watered conditions (Adiredjo et al. 2014).

\section{Plant culture, experimental design and root analysis}

The plants were grown in a growth chamber $\left(25^{\circ} \mathrm{C} / 20^{\circ} \mathrm{C}\right.$ in day/night) under $14 \mathrm{~h}$ of light $\left(200 \mu \mathrm{mol} \mathrm{m} \mathrm{m}^{-2} \mathrm{~s}^{-1}\right.$ photosynthetically active radiation at leaf level, Fluora, $\mathrm{L}$ $58 \mathrm{~W} / 77$, Germany) and $50 \pm 5 \% \mathrm{RH}$ in $250 \mathrm{~mL}$ pots. They were arranged in a randomized complete design with four RILs. To minimize the effects of heterogeneity within the growth chamber, the pots were rotated every week. Root hydraulics parameters (conductance, conductivity and contribution of AQPs) were measured by determining pressure-induced sap rates in six-week-old sunflower seedlings, when above-ground parts were 15$20 \mathrm{~cm}$ high. The experiment was repeated three times.

Seedlings were grown in $250 \mathrm{~mL}$ glass pots filled with sand which could be easily washed and saturated with solution and then introduced into the pressure chamber. Thus the root system did not have to be excavated before the pressure-induced flow experiment and thereafter, excavation of the roots from the cultivated sand substrate could be gently achieved under water for determination of root characteristics. Upon completion of the exudation experiments, root fresh weight was determined. Then, the properties i.e. root length, root surface area and volume of fine roots of each root system were determined with an image analyzer WinRHIZO 2007d (Regent Instruments, Quebec, Canada). Fine roots are the smallest diameter class $(0-0.5 \mathrm{~mm})$. Finally, root dry weight was measured.

\section{Measurement of root sap flow and $\mathrm{HgCl}_{2}$ treatment}

For pressure-flow experiments, upon harvest, pots were washed three times $(3 \times 50 \mathrm{~mL})$ to saturation with water for the control treatment and $\mathrm{HgCl}_{2}$ solution $(500 \mu \mathrm{M})$ for the inhibited treatment. Saturation of the pots allowed us to determine root conductivity since under non-limiting soil moisture, plant resistance exceeds soil resistance (in wet soil, the bulk soil potential is close to $0 \mathrm{MPa}$, Ruggiero et al. 1999; 2003). Following this washing, the aboveground part was cut off with a razor blade just below the cotyledonary leaves $(40-50 \mathrm{~mm}$ from the base). Pots with whole root systems were placed in a stainless steel pressure chamber (Soil Moisture Equipment Corp., Santa Barbara, CA, USA, Maggio and Joly 1995). Excised stems were sealed into the lid of the chamber through a silicone gasket so that part of the stem protruded and chamber pressure was gradually increased. Water expressed from each cut stem was collected using an Eppendorf tube 
containing dry cotton wool. The amount of sap was determined by weighing the tube before and after collection. The sap flow (Jv), expressed as the quantity of water exuded from the cut stems, was monitored every 5 min for at least $45 \mathrm{~min}$ after it had reached a constant rate (reached in less than $25 \mathrm{~min}$ ). Aliquots of expressed sap were collected from each root system for later analysis of $\mathrm{K}^{+}$content.

In preliminary experiments (pressure-flux curves), five pressures were applied in sequentially increasing order $(0.1,0.2,0.3,0.4$ and $0.5 \mathrm{MPa})$ to whole root systems. Flow values were logged for $25 \mathrm{~min}$ at each pressure, allowing a 5 -min equilibration period between pressures. Because the regression of sap flow on applied pressure was linear for all genotypes (data not shown), sap flows in both control and $\mathrm{HgCl}_{2-}$ treated plants were determined at a constant $0.3 \mathrm{MPa}$ pressure (Shimizu et al. 2005). Pressure was gradually increased up to $0.3 \mathrm{MPa}$ in the chamber, and was then held constant during the measurements (flow reached a steady-state value in about $20 \mathrm{~min}$ ). The sap flow (Jv) was then used to define (i) the whole root hydraulic conductance $\left(L_{0}\right)$ calculated as the sap flow rate per unit pressure $\left(\mu \mathrm{L} \mathrm{s}{ }^{-1} \mathrm{MPa}^{-1}\right)$ and (ii) the root hydraulic conductivity $\left(L p_{r}\right)$ calculated as the sap flow rate per unit root surface area and per unit pressure $\left(\mathrm{m} \mathrm{s}^{-1} \mathrm{MPa}^{-1}\right)$.

We performed preliminary experiments to determine the more suitable of two methods to treat the plants with the $\mathrm{HgCl}_{2}$ inhibitor. First, after measurement of the pressure that induced sap flow in untreated roots, the pressure was released slowly before opening the chamber, the cut stem was removed from the gasket and the pot was flushed with $\mathrm{HgCl}_{2}$ solution. The stem was once more sealed in the gasket secured to the lid and the pressure in the chamber again set to $0.3 \mathrm{MPa}$. However, this was a delicate procedure that often caused damage to the stem. Second, measurement of the pressure that induced sap flow was done on distinct root systems, untreated and treated (control and $\mathrm{HgCl}_{2}$ ). Therefore, calculation of the depressive effect of $\mathrm{HgCl}_{2}$ on $\mathrm{Jv}$ was finally achieved by considering the second method rather than the first since both gave similar results.
Experiments were performed three times using three plants per RIL each time.

After flushing the pot with $\mathrm{HgCl}_{2}$, maximal inhibition was achieved in less than $40 \mathrm{~min}$. The reversibility of inhibition by $\mathrm{HgCl}_{2}$ of pressure-induced sap flow was evaluated by flushing of the pot with $3 \times 50 \mathrm{~mL} 10 \mathrm{mM}$ mercaptoethanol (ME) . The decrease brought about by $\mathrm{HgCl}_{2}$ was reversed by ca $90 \%$ on subsequent treatment for 30 min with ME. Some sap samples collected from control or $\mathrm{HgCl}_{2}$-treated de-topped plants were diluted ( $c a 40 \mu \mathrm{L}$ of sap $+1 \mathrm{~mL} \mathrm{H}_{2} \mathrm{O}$ ) and injected into a Dionex-D-100 ion chromatograph (USA). $\mathrm{K}^{+}$flux through the xylem was calculated as the product of the sap flux and concentration of $\mathrm{K}^{+}$in the sap.

\section{Statistics}

Data were analyzed with the PASW statistics 18 (IBM, New York, USA) package. We used the Least Significant Difference $(\mathrm{LSD})$ test $(P<0.05)$ to make post-hoc comparisons between all means. Percentages of inhibition by $\mathrm{HgCl}_{2}$ were calculated for each individual root system, and mean values and standard deviations were calculated for the three experiments. In total, the response of nine $\mathrm{HgCl}_{2}$-treated plants was compared with those of untreated plants for each genotype.

\section{Results}

\section{Size of root systems}

Morphological parameters of sunflower root systems are presented in Table 1. RIL 043 and RIL 127 had the largest and the smallest root systems for every parameter (fresh or dry mass, surface, length and fine root volume), respectively. Differences reached up to $100 \%$ of the values, demonstrating considerable variation in root morphology between genotypes. RIL 149 and RIL 200 showed intermediate root characteristics with the ranking: RIL149 > RIL200.

\section{Variation of root hydraulic properties}

Figure 1 shows a representative time course of cumulative water movement of a root system before (control) and after treatment with $\mathrm{HgCl}_{2}$ for the four sunflower

Table 1 Root morphological parameters and $\mathrm{K}^{+}$flux into the xylem of four sunflower genotypes grown in a growth chamber under controlled and well-watered conditions

\begin{tabular}{|c|c|c|c|c|c|c|c|}
\hline Genotype & $N$ & RFW (g) & $\mathrm{RDW}(\mathbf{g})$ & $\mathrm{RL}(\mathrm{cm})$ & $\mathrm{RS}\left(\mathrm{cm}^{2}\right)$ & $\operatorname{RV}\left(\mathrm{cm}^{3}\right)^{a}$ & $\mathrm{~K}^{+}$flux $\left(\mu \mathrm{mol} \mathrm{h}^{-1} \mathrm{~g}^{-1}\right)$ \\
\hline RIL043 & 23 & $7.92 \pm 2.08$ & $0.29 \pm 0.06$ & $1669 \pm 331$ & $210 \pm 35$ & $2.39 \pm 0.74$ & $5.08 \pm 0.10(92.6 \%)$ \\
\hline RIL127 & 19 & $3.16 \pm 0.68$ & $0.17 \pm 0.05$ & $1191 \pm 211$ & $134 \pm 31$ & $1.05 \pm 0.43$ & $2.11 \pm 0.55(121.6 \%)$ \\
\hline RIL 149 & 20 & $5.23 \pm 0.95$ & $0.24 \pm 0.07$ & $1271 \pm 264$ & $161 \pm 30$ & $1.63 \pm 0.42$ & $1.76 \pm 0.11(103.3 \%)$ \\
\hline RIL200 & 23 & $7.21 \pm 1.86$ & $0.27 \pm 0.08$ & $1247 \pm 457$ & $152 \pm 40$ & $2.01 \pm 0.69$ & $6.72 \pm 1.23(116.2 \%)$ \\
\hline
\end{tabular}

$\mathrm{N}$ : number of roots, RFW: root fresh weight, RDW: root dry weight, RL: root length, RS: root surface, RV: fine root volume.

The data represent all the roots of the non-inhibited plants (control) and inhibited plants $\left(\mathrm{HgCl}_{2}\right)$. Values are means and standard deviations.

${ }^{\mathrm{a}}$ Fine roots are the smallest diameter class $(0-0.5 \mathrm{~mm})$ determined by the WinRHIZO analysis.

${ }^{\mathrm{b}} \mathrm{K}^{+}$fluxes are for $\mathrm{HgCl}_{2}$ treated plants but are also expressed in percentage of the controls (values in parenthesis). 


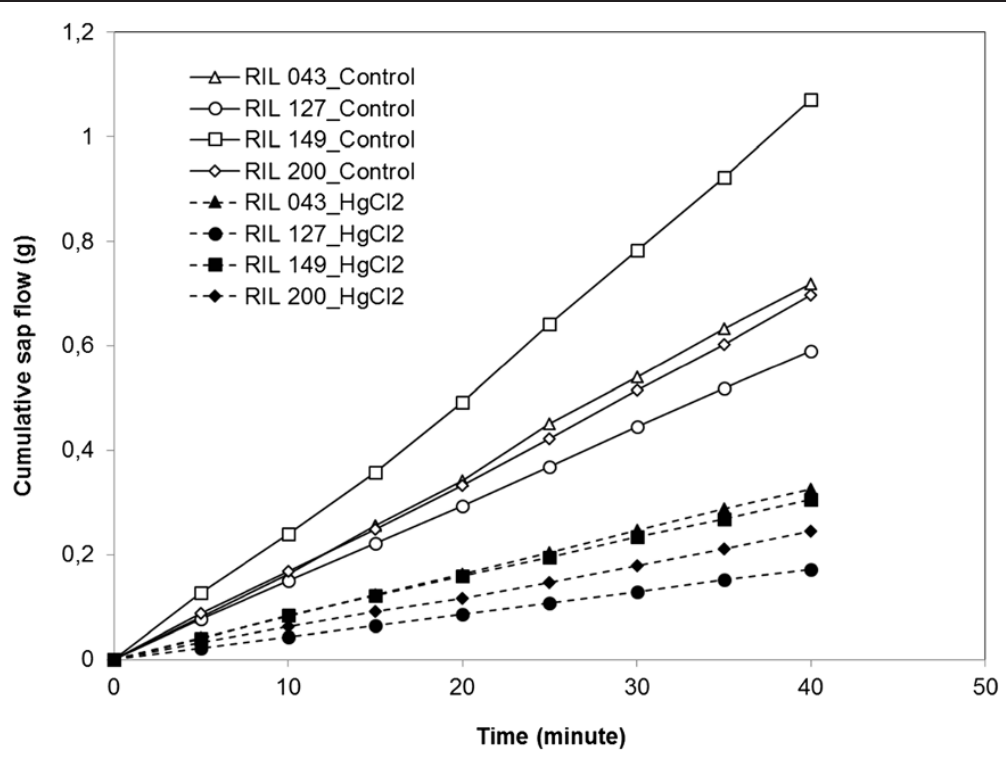

Figure 1 The figure shows an example of cumulative sap flow for one root system per RIL and per treatment (open symbols for control and solid symbols for $\mathrm{HgCl}_{2}$ ) of RIL 043 , RIL 127, RIL 149, RIL 200. The cumulative data were obtained from eight successive, five minutes apart.

RILs. Sap flow (Jv) from untreated or treated root systems remained virtually constant throughout the $40 \mathrm{~min}$ measurement period. The ranking of RILs for Jv in untreated root systems was RIL149 > RIL43 = RIL200 > RIL127. Pressure-induced sap flow was almost twice as high in RIL 149 as in RIL 127. The sap flow was strongly inhibited by $\mathrm{HgCl}_{2}$ treatment in all genotypes (more than 50\%).

Mean values of $L_{O}$ and $L p_{r}$ showed significant variation between the four RILs. The values ranged from 0.7 to $1.2 \mu \mathrm{L} \mathrm{s}^{-1} \mathrm{MPa}^{-1}$ and $5.10^{-8}$ to $8.10^{-8} \mathrm{~m} \mathrm{~s}^{-1} \mathrm{MPa}^{-1}$, respectively. The ranking of RILs for $L_{O}$ was RIL $149>$ RIL $043>=$ RIL $200>$ RIL 127 but the ranking was changed for $L p_{r}$ : RIL $149>$ RIL $200>$ RIL $127>$ RIL 043. Differences between extreme values were above $60 \%$ in both cases.

\section{Contribution of AQPs to water uptake}

In our experiment, the contribution of AQPs to sap flow was explored using mercuric chloride. $L_{O}$ and $L p_{r}$ fell to $30-40 \%$ of the control value and differences appeared between RILs (Figure $2 \mathrm{~A}$ and $\mathrm{B}$ ). $\mathrm{HgCl}_{2}$-treated root systems displayed markedly different $L_{O}$ values between genotypes (Figure 2A) which ranked as follows: RIL $043>$ RIL $149>$ = RIL $200>$ RIL 127 ( $L_{O}$ for RIL 043 was about 70\% higher than for RIL 127). By contrast, $L p_{r}$ values were similar for all four RILs following $\mathrm{HgCl}_{2}$ treatment (Figure 2B).

The contribution of AQPs to $L p_{r}$ (AQP involvement) expressed as the relative decrease in $L p_{r}$ induced by $\mathrm{HgCl}_{2}$ treatment was the highest in RIL 149 (73\%) and the lowest in RIL 043 (55\%) while other RILs displayed an intermediate contribution (Figure 3 ).

The flux of $\mathrm{K}^{+}$into the xylem was not significantly affected by the presence of $\mathrm{HgCl}_{2}$ corresponding to $92.6 \%$, $121.6 \%, 103.3 \%$ and $116.2 \%$ of the controls for RIL 043, RIL 127, RIL 149 and RIL 200, respectively (Table 1).

\section{Discussion}

In this study, the values of $L p_{r}$ for sunflower root systems ranged from $5.10^{-8}$ to $8.10^{-8} \mathrm{~m} \mathrm{~s}^{-1} \mathrm{MPa}^{-1}$ and were within the range of values reported for other species (Liu et al. 2009; Sutka et al. 2011, Sakurai-Ishikawa et al. 2011), although rather at the lower end of the $L p r$ scale reported for roots of annual (crop) plants. Our values for sunflower root hydraulic conductivity were very similar to those reported for roots of 20-d-old sunflower plants (ca $600 \mu \mathrm{L} \mathrm{h}^{-1} \mathrm{~g}^{-1}$ root fresh weight $\mathrm{MPa}^{-1}$, see Figure 1 and Table 1, Quintero et al. 1999) but Alfalfa had $L p_{r}$ values 10 times higher than sunflower (Li et al. 2007). The pressure that induces flow through root systems has been considered by some authors (Li et al. 2007; Liu et al. 2009) to be inappropriate to characterize "absolute" hydraulic values, because the externally applied pressure can induce flow through pathways external to the root system. Indeed, pressure chamber experiments give higher values of $L p_{r}$ than other methods using root pressure probes: resistance may vary according to the nature of the driving force for water movement (osmotic versus hydraulic) and the flow rate (Liu et al. 2009). It has been shown by Vandeleur et al. (2014) that shoot manipulation affected root 

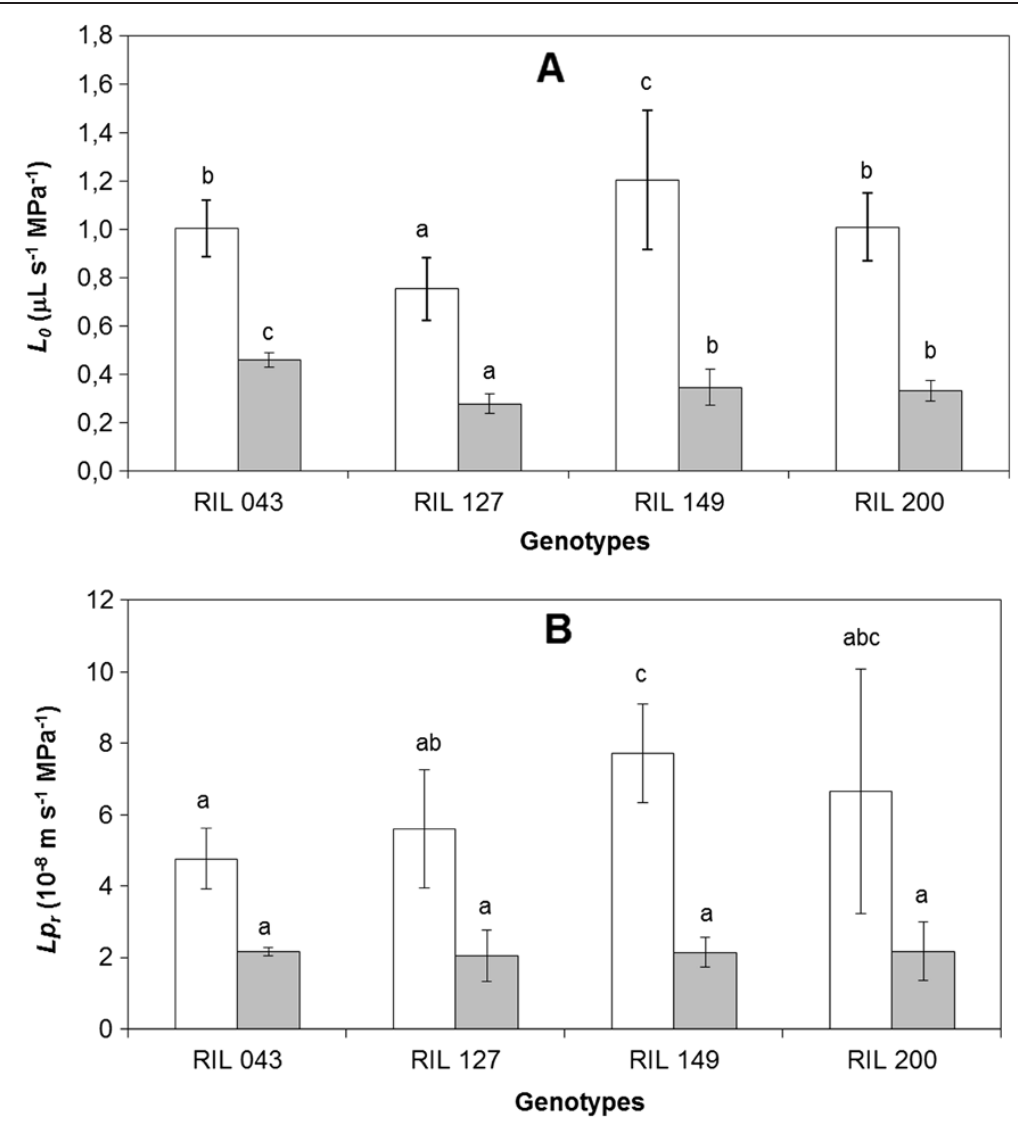

Figure 2 Means of $L_{o}(\mathrm{~A})$ and $L p_{r}$ (B) of RIL 043, RIL 127, RIL 149, RIL 200. The white bars are non-inhibited plants (control) and the black bars are inhibited plants $\left(\mathrm{HgCl}_{2}\right)$. Each value is the mean of nine plants \pm standard deviation. Means within a treatment without a common letter are significantly different by $\mathrm{LSD}_{0.05}$ test.

hydraulic characteristics in grapevine, soybean and maize. Here, we used detopped plants to measure root hydraulics, thus a note of caution is warranted regarding the absolute values reported. However, the purpose of the present work was to compare the hydraulics of several sunflower RILs differing in their whole-plant water relationships. Root $L p$ has been repeatedly shown to change with the volume flow rate through the root system (Sakurai-Ishikawa et al. 2011, Laur and Hacke 2013). However, the flow rates induced here through

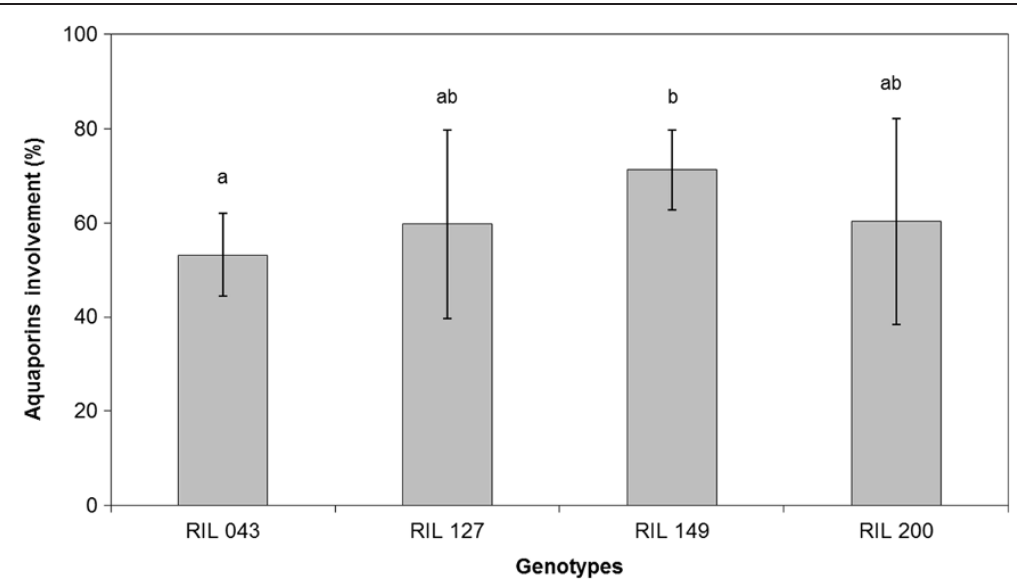

Figure 3 Means of involvement of aquaporins of RIL 043, RIL 127, RIL 149, RIL 200. Each value is the mean of nine plants \pm standard deviation. Means without a common letter are significantly different by $\mathrm{LSD}_{0.05}$ test. 
pressure gradient across isolated root systems were similar to transpirational water loss rates of intact plants of the same age (Adiredjo et al. 2014).

Mercuric chloride-induced reversible inhibition of root water flow is consistent with the presence of a proteinmediated path for trans-membrane sap flow in the sunflower root. To avoid non-specific effects, concentrations have to be as low as possible and exposure time as short as possible. Coskun et al. (2012) recommended caution when using aquaporin inhibitors including $\mathrm{Hg}^{2+}$. They showed membrane damage resulting from $500 \mu \mathrm{M} \mathrm{Hg}^{2+}$. Here we used the same relatively high $\mathrm{HgCl}_{2}$ concentration $(500 \mu \mathrm{M})$. However, this value was similar to concentrations used in previous studies on whole root systems (Maggio and Joly 1995; Peyrano et al. 1997; Shimizu et al. 2005; Ruggiero et al. 2007). In addition, considering that we worked with sand (in which root excretion of organic compounds creates an organic matrix) and not in a hydroponics set-up, the effective concentration in the root zone was probably far below $500 \mu \mathrm{M}$ due to immobilization of part of the $\mathrm{Hg}^{2+}$ by the system (Ruggiero et al. 2007). The concentration used in this study was chosen from the preliminary dose response curves performed to identify a threshold concentration that had a marked effect on sap flow (for instance, $50 \mu \mathrm{M} \mathrm{HgCl}$ did not induce any depressive effect on sap flow) but that did not cause apparent irreversible toxicity effects. Indeed, the relationship between sap flow and applied pressure was highly linear suggesting that the $\mathrm{Hg}$ treatment did not cause broadly deleterious changes in root function during the time course of the pressure flow procedure (Maggio and Joly 1995). In addition, there was no significant difference between control and $\mathrm{HgCl}_{2}$-treated roots in the amount of $\mathrm{K}^{+}$recovered in the xylem exudates delivered through whole-root systems demonstrating that the $\mathrm{Hg}^{2+}$ concentration and exposure durations used here did not poison root cells in a way that might cause them to become leaky to ions (Maggio and Joly 1995). Another convincing argument concerning the lack of general toxicity is the reversal of mercuric chloride inhibition by the scavenger 2mercaptoethanol which is assumed to remove $\mathrm{Hg}$ from membranes of treated roots (Barrowclough et al. 2000). Inhibition of sap flow by $\mathrm{HgCl}_{2}$ was reversed by $c a 90 \%$ following rinsing of the root system in a mercaptoethanol solution $(10 \mathrm{mM})$. In addition, sap continued to be spontaneously expressed from cut stems of excised roots several hours after mercury application demonstrating the generation of strong root pressure in the treated roots. Altogether these results indicate that $\mathrm{HgCl}_{2}$ did not reduce sap flow by a general inhibition of root metabolism, but rather by a direct effect on AQPs.

Leaves need to be continuously supplied with water and carbon dioxide to fulfill their photosynthetic function. The water transport capacity of the root $\left(L_{0}\right.$, root hydraulic conductance) is thus a key physiological parameter for whole-plant function since it determines the interplay between sap flow intensity and water potential gradients between soil and leaves. Differences in whole $L_{O}$ reached a high value of $60 \%$ between sunflower genotypes. $L_{O}$ was highest for RIL 149 and lowest for RIL 127 while RIL 043 and RIL 200 had similar intermediate values. $L_{O}$ reflects the overall water uptake capacity of the root and results from both the root exchange surface area and its intrinsic water transport capacity $\left(L p_{r}\right) . L p_{r}$ had a different ranking from $L_{0}$, with the highest value for RIL 149 (as observed for $L_{O}$ ) but the lowest for RIL 043 (whereas it was in second position for $L_{O}$ ). $L p_{r}$ in RIL 049 was found to be $70 \%$ higher than in RIL 043. $L p_{r}$ was expressed in relation to the whole root area, assuming that outer cell layers were consistently representative of the hydraulic properties of all the segments of the root system (Sutka et al. 2011). We also checked that when $L p_{r}$ was expressed in relation to root length or fine root volume, a similar difference between RIL 149 and RIL 043 was observed (see Table 1). Thus, genotype (RIL 043) can display both high whole root capacity $\left(L_{O}\right)$ and small intrinsic root capacity $\left(L p_{r}\right)$. Sutka et al. (2011) described a substantial (2-fold) genetic variation in $L p r$, establishing that Arabidopsis root hydraulic properties are far from uniform between natural accessions. We show here that large variations in root hydraulics also appear between sunflower genotypes.

$L p_{r}$ was sensitive to brief treatment with $\mathrm{HgCl}_{2}$. This allows $L p_{r}$ to be divided into two components: cell to cell and apoplastic pathways (ignoring the dilution-diffusion process across the double layer of membrane lipids which is not sensitive to mercury). The $L p_{r}$ of apoplasmic pathways, i.e. $L p_{r}$ measured in $\mathrm{HgCl}_{2}$, was identical for all genotypes. In other words, the conductance of the AQP-independent pathway (on an area basis) was similar for all RILs. Tissue mass, organization and/or cell wall structure (suberization of apoplastic barriers usually associated with root maturation which reduces water uptake capacity) may affect intrinsic root hydraulics. However, Sutka et al. (2011) reported that Arabidopsis accessions did not show any clear link between root suberization and the hydraulic conductivity of the AQP-independent path. In the present work, although sunflower genotypes displayed evident variations in root anatomy, no variations were observed in "intrinsic" apoplastic conductivity ( $L p_{r}$ in $\mathrm{HgCl}_{2}$ treated roots). This suggests that the cell-to-cell pathway (aquaporin-dependent) was the major determinant of the "intrinsic" water transport properties of the organ ( $L p_{r}$ in control plants),RIL 149 showing the highest involvement of AQPs (72\%) and RIL 043 the lowest (55\%). The relative contribution of AQPs to root conductivity (average $60 \%$ in the present experiment with sunflower) was similar to other estimates obtained in herbaceous species (Maggio and Joly 1995; Tazawa et al. 1997; 
Carvajal et al. 1999; Barrowclough et al. 2000; Shimizu et al. 2005; Sutka et al. 2011; Ruggiero et al. 2007) confirming that pathways not involving AQPs can make a significant contribution to $L p_{r}$ (around 40\%).

In the present study, sunflower genotypes were selected because of their contrasting behaviour with respect to water under well-watered conditions (Adiredjo et al. 2014). A variety of hydraulic profiles can be observed between the four sunflower genotypes. RIL 149 and RIL 043 had the highest $L_{O}$ but exhibited interesting and differing root properties. It appears that a "large" root anatomy (i.e. large root surface area, volume, and mass) allows RIL 043 to compensate for its lower contribution of AQPs to root hydraulics and therefore its lower $L p_{r}$. Whole $L_{0}$ was only slightly lower in RIL 043 than in RIL 149, which had a greater $L_{0}$ and the greatest $L p_{r}$ due to high AQP involvement. By contrast, RIL 127 had the lowest whole $L_{O}$ due to small root development, despite higher intrinsic $L p_{r}$ and contribution of AQPs than RIL 043. RIL 200 exhibited intermediate values for all parameters. Interestingly, the ranking of the RILs for $L_{O}$ was the same as the ranking of the RILs for WUE determined in our previous study: RIL $149>$ RIL $043>$ RIL $200>$ RIL 127 (Adiredjo et al. 2014). Therefore, $L_{O}$ is suggested to play a key role in sunflower water balance and WUE (Maurel 2007; Sade et al. 2010). AQPs are reported to be regulated by several stresses, particularly drought, and shoots transpiration (Martre et al. 2001, 2002; Clarkson et al. 2000; Martínez-Ballesta et al. 2003; Shimizu et al. 2005; Sakurai-Ishikawa et al. 2011; Laur and Hacke 2013; Chaumont and Tyerman 2014) often without any change in root anatomy or morphology. Under stress conditions, RIL 043, which displays the highest water transport capacity of the whole organ due to extensive root development, could be less affected than RIL 149 which presents high water transport capacities that depend on the contribution of AQPs.

\section{Conclusions}

Three main conclusions emerge from our results: (i) a large variation occurs in morphological and hydraulic profiles in sunflower, (ii) there is a varying contribution of AQPs to hydraulic conductivity but a similar root intrinsic water permeability ( $L p_{r}$, on an area basis) between genotypes and (iii) root anatomy, which appears to be a major determinant of the water transport properties of the whole organ, is able to compensate for a low AQP contribution.

\section{Competing interests}

The authors declare that they have no competing interests.

Authors' contributions

All authors read and approved the final manuscript.

\section{Acknowledgments}

Afifuddin Latif Adiredjo was supported by a French Government scholarship (Bourse du Gouvernement Français, BGF) and a co-funding by Directorate General of Higher Education, Ministry of Education and Culture, Republic of Indonesia (Beasiswa Luar Negeri, BLN).

Philippe Grieu and Thierry Lamaze are Ph.D. supervisors of the first author.

\section{Author details}

'Université de Toulouse, INP - ENSAT, UMR 1248 AGIR (INPT-INRA), BP 52627, Castanet-Tolosan 31326, France. ${ }^{2}$ Brawijaya University, Faculty of Agriculture, Department of Agronomy, Plant Breeding Laboratory, Veteran street, Malang 65145, Indonesia. ${ }^{3}$ Université de Toulouse, UPS - Toulouse III, UMR 5126 CESBIO, 18 avenue Edouard Belin, Toulouse, Cedex 9 31401, France.

Received: 9 June 2014 Accepted: 23 October 2014

Published online: 30 October 2014

\section{References}

Adiredjo AL, Navaud O, Lamaze T, Grieu P (2014) Leaf carbon isotope discrimination as an accurate indicator of water use efficiency in sunflower genotypes subjected to five stable soil water contents. J Agron Crops Sci, in press

Barrowclough DE, Peterson CA, Steudle E (2000) Radial hydraulic conductivity along developing onion roots. J Exp Bot 51:547-557

Carvajal M, Cooke DT, Clarkson DT (1996) Responses of wheat plants to nutrient deprivation may involve the regulation of water-channel function. Planta 199:372-381

Carvajal M, Martinez V, Alcaraz CF (1999) Physiological function of waterchannels, as affected by salinity in roots of paprika pepper. Physiol Planta 105:95-101

Chaumont F, Tyerman SD (2014) Aquaporins: highly regulated channels controlling plant water relations. Plant Physiol 164:1600-1618

Chaumont F, Moshelion M, Daniels MJ (2005) Regulation of plant aquaporin activity. Biol Cell 97:749-764

Clarkson DT, Carvajal M, Henzler T, Waterhouse RN, Smyth AJ, ooke DT, Steudle E (2000) Root hydraulic conductance: diurnal aquaporin expression and the effects of nutrient stress. J Exp Bot 51:61-70

Coskun D, Britto DT, Jean Y-K, Schulze LM, Becker A, Kronzucker HJ (2012) Silver ions disrupt $\mathrm{K}^{+}$homeostasis and cellular integrity in intact barley (Hordeum vulgare L.) roots. J Exp Bot 63:151-162

Grieu P, Maury P, Debaeke P, Sarrafi A (2008) Ameliorer la tolerance a la secheresse du tournesol: apports de l'ecophysiologie et de la genetique. Innovat Agronomiques 2:37-51

Heinen RB, Ye Q, Chaumont F (2009) Role of aquaporins in leaf physiology. J Exp Bot 60:2971-2985

Kamaluddin M, Zwiazek JJ (2001) Metabolic inhibition of root water flow in red-osier dogwood (Cornus stolonifera) seedlings. J Exp Bot 52:739-745

Laur J, Hacke UG (2013) Transpirational demand affects aquaporin expression in poplar roots. J Exp Bot 64:2283-2293

Li WR, Zhang SQ, Shan L (2007) Effects of water stress on characteristics of root water uptake and photosynthesis in alfalfa seedlings. Acta Agres Sin 15:206-211

Liu B, Steudle E, Deng XP, Zhang SQ (2009) Root pressure probe can be used to measure the hydraulic properties of whole root systems of corn (Zea mays L.). Bot Stud 50:303-310

Maggio A, Joly RJ (1995) Effects of mercuric chloride onthe hydraulic conductivity of tomato root systems. Evidence fora channel-mediated water pathway. Plant Physiol 109:331-335

Martínez-Ballesta MC, Aparicio F, Pallás V, Martínez V, Carvajal M (2003) Influence of saline stress on root hydraulic conductance and PIP expression in Arabidopsis. J Plant Physiol 160:689-697

Martre P, North GB, Nobel PS (2001) Hydraulic conductance and mercurysensitive water transport for roots of Opuntia acanthocarpa in relation to soil drying and rewetting. Plant Physiol 126:352-362

Martre P, Morillon R, Barrieu F, North GB, Nobel PS, Chrispeels MJ (2002) Plasma membrane aquaporins play a significant role during recovery from water deficit. Plant Physiol 130:2101-2110

Maurel C (2007) Plant aquaporins: novel functions and regulation properties FEBS Lett 581:2227-2236

North GB, Martre P, Nobel PS (2004) Aquaporins account for variations in hydraulic conductance for metabolically active root regions of Agave deserti in wet, dry, and rewetted soil. Plant Cell Environ 27:219-228 
Ouvrard O, Cellier F, Ferrare K, Tousch D, Lamaze T, Dupuis J-M, Casse-Delbart F (1996) Identification and expression of water stress and abscisic acid-regulated genes in a drought tolerant sunflower genotype. Plant Mol Biol 31:819-829

Pasda G, Diepenbrock W (1990) The physiological yield analysis of sunflower (Helianthus annuus L.) Part II Climatic factors. Fett Wissenschfat Tech 93:155-168

Peyrano ET, Quiroga M, de Forchetti SM, Tigier H (1997) Salinity effects on hydraulic conductance, lignin content and peroxidase activity in tomato roots. Plant Physiol Biochem 35:387-393

Quintero JM, Fournier JM, Benlloch M (1999) Water transport in sunflower root systems: effects of $\mathrm{ABA}, \mathrm{Ca}^{2+}$ status and $\mathrm{HgCl}_{2}$. J Exp Bot 50:1607-1612

Rawson HM, Constable GA, Howe GN (1980) Carbon production of sunflower cultivars in field and controlled environment. II. Leaf Growth. Aust J Plant Physiol 7:575-586

Rengel D, Arribat S, Maury P, Magniette MLM, Hourlier T, Laporte M, Vares D, Carrère S, Grieu P, Balzergue S, Gouzy J, Vincourt P, Langlade NB (2012) A gene-phenotype network based on genetic variability for drought responses reveals key physiological processes in controlled and natural environments. PLoS One 7:e45249

Ruggiero C, De Pascale S, Fagnano M (1999) Plant and soil resistance to water flow in fababean (Vicia Faba L. major Harz.). Plant Soil 210:219-231

Ruggiero C, de Pascale S, Angelino G, Maggio A (2003) Developmental changes in plant resistance to water flow in Pisum sativum (L.). Plant Soil 250:121-128

Ruggiero C, Angelino G, Maggio A (2007) Developmental regulation of water uptake in wheat. J Plant Physiol 164:1170-1178

Sade N, Gebretsadik M, Seligmann R, Schwartz A, Wallach R, Moshelion M (2010) The role of tobacco aquaporin1 in improving water use efficiency, hydraulic conductivity, and yield production under salt stress. Plant Physiol 152:245-254

Sakurai-Ishikawa J, Murai-Hatano M, Hayashi H, Ahamed A, Fukushi K, Matsumoto T, Kitagawa Y (2011) Transpiration from shoots triggers diurnal changes in root aquaporin expression. Plant Cell Environ 34:1150-1163

Sarda X, Tousch D, Ferrare K, Legrand E, Dupuis JM, Casse-Delbart F, Lamaze T (1997) Two TIP-like genes encoding aquaporins are expressed in sunflower guard cells. Plant J 12:1103-1111

Sarda X, Tousch D, Ferrare K, Cellier F, Alcon C, Dupuis JM, Casse F, Lamaze T (1999) Characterization of closely related d-TIP genes encoding aquaporins which are differentially expressed in sunflower roots upon water deprivation through exposure to air. Plant Mol Biol 40:179-191

Savage DF, Stroud RM (2007) Structural basis of aquaporin inhibition by mercury. J Mol Biol 368:607-617

Shimizu M, Ishida A, Hogetsu T (2005) Root hydraulic conductivity and wholeplant water balance in tropical saplings following a shade-to-sun transfer. Oecologia 143:189-197

Steudle E, Peterson CA (1998) How does water get through roots? J Exp Bot 49:775-788

Steudle E, Oren R, Schulze ED (1987) Water transport in maize root. Plant Physiol 84:1220-1232

Sutka M, Li G, Boudet J, Boursiac Y, Doumas P, Maurel C (2011) Natural variation of root hydraulics in Arabidopsis grown in normal and salt-stressed conditions. Plant Physiol 155:1264-1276

Tazawa M, Ohkuma E, Shibasaka M, Nakashima S (1997) Mercurial-sensitive water transport in barley roots. J Plant Res 110:435-442

Vandeleur RK, Sullivan W, Athman A, Jordans C, Gilliham M, Kaiser BN, Tyerman SD (2014) Rapid shoot-to-root signalling regulates root hydraulic conductance via aquaporins. Plant Cell Environ 37:520-538

Vincourt P, As-sadi F, Bordat A, Langlade NB, Gouzy J, Pouilly N, Lippi Y, Serre F, Godiard L, De Labrouhe DT, Vear F (2012) Consensus mapping of major resistance genes and independent QTL for quantitative resistance to sunflower downy mildew. Theor Appl Genet 125:909-920

Wan X, Zwiazek JJ (1999) Mercuric chloride effects on root water transport in aspen seedlings. Plant Physiol 121:939-946

Zhang WH, Tyerman SD (1999) Inhibition of water channels by $\mathrm{HgCl}_{2}$ in intact wheat root cells. Plant Physiol 120:849-857

doi:10.1186/s40529-014-0075-1

Cite this article as: Adiredjo et al:: Hydraulic conductivity and contribution of aquaporins to water uptake in roots of four sunflower genotypes. Botanical Studies 2014 55:75.

\section{Submit your manuscript to a SpringerOpen ${ }^{\odot}$ journal and benefit from:}

- Convenient online submission

- Rigorous peer review

- Immediate publication on acceptance

- Open access: articles freely available online

- High visibility within the field

- Retaining the copyright to your article

Submit your next manuscript at $\gg$ springeropen.com 